American Journal of Pharmacology and Toxicology 6 (2): 33-36, 2011

ISSN 1557-4962

(C) 2011 Science Publications

\title{
Inhibition of Skin Colour Darkening (Skin Clearing and Lightening); Skin Firming; Body Calming and Body Vitalizing Effects of Vernonia amygdalina Leaf Extract
}

\author{
Utoh-Nedosa Uchechukwu Anastasia \\ Department of Pharmacology and Toxicology, Faculty of Pharmaceutical Sciences; \\ Nnamdi Azikiwe University, Awka, Anambra State, Nigeria
}

\begin{abstract}
Problem statement: Obese human subjects treated with oral Vernonia amygdalina $(V$. amygdalina) aqueous leaf extract for one month who experienced the anti-obesity effects of $V$. amygdalina leaf extract reported a lighter; clearer; more glowing and firmer skin as side effects of the treatment (unpublished findings). In this study, oral Vernonia amygdalina aqueous leaf extract was taken daily for six months to observe its effects on the external appearance and the firmness of the skin of the treated subject. Approach: Vernonia amygdalina leaf extract was prepared as a leaf effusion. The extract was taken 4 times daily by the subject who also oserved some dietary restritions. Results: The results of the study showed that $V$. amygdalina leaf extract has potent skin clearing; skin firming; skin lightening (inhibition of skin colour darkening); skin texture and lusture restoration; anti-obesity; body calming and body vitality (vigor) effects. These skin colour and form restoration effects of $V$. amygdalina extract coupled to its body metabolism effects to give body calm, vitality and youthful looks to the subject. Conclusion: The study concludes that $V$. amygdalina leaf extract has skin colour and formlightening and restoration effects as well as body calming and body vitalizing effects.
\end{abstract}

Key words: Skin colour darkening, leaf extract, lusture restoration, skin texture, dietary restrictions, body calming, sun flower seed, Nigerian pea, artificial salt, alcoholic drinks, visible effects, obese human

\section{INTRODUCTION}

Obese human subjects treated with oral Vernonia amygdalina (V. amygdalina) leaf extract for one month who experienced the anti-obesity effects of $V$. amygdalina leaf extract reported a lighter; clearer; more glowing and firmer skin and a calming effect on the body as side effects of the treatment (unpublished findings).

$V$. amygdalina leaf extract has been shown to have antioxidant; antibacterial; antifungal; anthelmintic; antithrombosis; lipid lowering; anti-diabetic; wound healing and anti-cancer properties (Alkassasbeh et al., 2009; Al-Akhras et al., 2007; Harrison and Bartels, 2006).

Skin lightening and skin tightening effects of $V$. amygdalina extract has not been reported in humans although a study observed skin lightening effects of $V$. amygdalina in rats whose feed was enhanced with ground V. amygdalina leaves (Abu-Al-Basal, 2009). This study investigated the externally visible effects of $V$. amygdalina leaf extract on human skin and body energy level.

\section{MATERIALS AND METHODS}

An Infusion of fragments of dried wholesome mature red stalked $V$. amygdalina (bitter leaf) leaves was made by putting them in twice their own volume of boiling drinking water in a clean cooking pot. Stirring of the leaf fragments for 10-15 min enhanced complete effusion of the $V$. amygdalina leaf extract into the boiling water.

Treatment: The treatment consisted of the oral intake of the $V$. amygdalina leaf extract and the observation of stipulated eating behavior by the human subject.

The subject took $70 \mathrm{~m} \mathrm{~L}$ of the $V$. amygdalina leaf infusion orally 4 times daily; for six months while observing the following listed dietary restrictions.

Dietary restrictions: The subject abstained from the following foods: lard; vegetable oil; butter/margarine; mayonnaise; grated coconut; bacon; ground nut/peanut butter; nuts like palm nut, coconut, date palm; oil fried foods; oily seeds like beniseed, egusi, sun flower seed; oily fruits like avocado pea, Nigerian pea ; oily soups, stews or gravies; oily cooked or prepared meals like 
salads, bean cakes and from pastries or flour foods like dough nuts, burns, cakes, spaghetti/ macaroni, bread; alcohol or alcoholic drinks; beverages; soft drinks (including malt drinks and carbonated drinks); tobacco or tobacco products; garlic and acidic food spices and condiments; artificial food seasoning (artificial salt or salt substitutes including potash).

Permitted diet and eating behavior: The subject's meals consisted of two daily meals which contained their normal daily requirements of proteins, nonacidic fruits; mineral salts and water. Only one third of the carbohydrates meals and one tenth of the fats and oils previously consumed by the researcher was eaten by the researcher. Two thirds of the carbohydrates which the subject previously consumed were replaced by leafy green vegetables.

\section{RESULTS}

The treated subject reported that her body felt more calm and relaxed and functioned with a new energy of a more efficient type. The subject also reported being full of new strength and zest and having lost excess body fat. The skin effects reported by the subject included a smoother skin; a skin that was healthier and tighter on the muscles of the flesh; a cleared and shinnier skin and a restored skin color.

Figure $1 \mathrm{~b}$ shows the subject before the $V$. amygdalina leaf extract treatment. A comparism of the before and after treatment physical looks of the treated subject showed that $V$. amygdalina leaf extract produced the following results observable in the pictures in Fig. 1a and c-e:

- It restored the subject's light skin colour in (Fig. 1a and c-e)

- It cleared the skin blemishes (skin infections and discolorations) (Fig. 1a and c-e).The clearance of the skin by the extract made the skin to look clear and transparent as exemplified by the fingers of the raised left hand in Fig. 1e

- It tightened the skin texture and smoothened the skin surface. The firming and smoothening of the skin by the $V$. amygdalina extract is seen in Fig. 1a and c-e but is best demonstrated on the face in Fig. 1b and on the face and shoulders in Fig. 1c

- It restored the lusture (a reflective shine) and glow of the skin. The bright shining glow of the skin is present in Fig. 1a and c-e and is most visible on the fore heads in the Fig. 1b-e and at the skin covering the clavicle in Fig. 1c

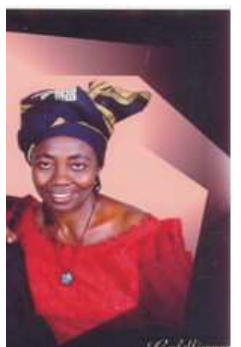

(a)

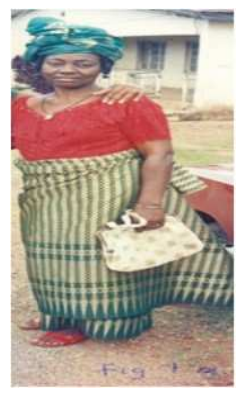

(b)

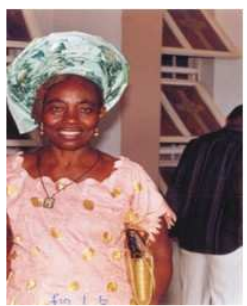

(c)

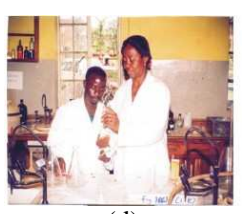

(d)

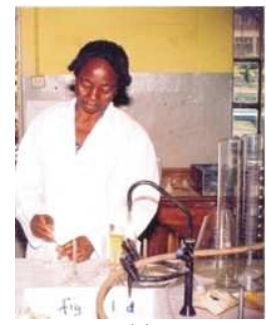

(e)

Fig. 1a and c-e: Show the effect of oral Vernonia amygdalina leaf extract treatment on the subjec's skin colour, skin texture, skin smoothness, skin lusture, skin firmness; body calmness and vitality, (b) Shows the subject before the oral Vernonia amygdalina leaf extract treatment 
A comparism of the external features of the body in Fig. 1a with those in Fig. 1b-e shows that the $V$. amygdalina leaf extract treatment produced a calming effect on the body. The body of the subject was functioning in a more relaxed state or at a lower energy level after the $V$. amygdalina treatment than before it.

\section{DISCUSSION}

The skin clearing effects of $V$. amygdalina leaf extract are suggested to be due to the clearing of skin infections and minor skin blemishes through the demonstrated antimicrobial (Krishna et al., 2009) antiparasitic and immune defence and antioxidant properties of $V$. amygdalina leaf extract.

The skin tightening and skin texture and lusture restoration effects of $V$. amygdalina obtained in this study is suggested to be as a result of the excess fat reduction effects (Kim et al., 2006); the immune defence properties; the body organ repair properties (Liu et al., 2005; Nayak, 2006; Sudha et al., 2009; Tong-Un et al., 2010) and the direct skin tightening effects of $V$. amygdalina leaf extract.

The natural skin colour restoration effects of $V$. amygdalina demonstrated in this study is as a result of the inhibition of the darkening of the melanophores of the skin of the subject by infective and other agents.

The skin of Wistar rats fed for 65 days with 25, 50 and $75 \%(\mathrm{w} / \mathrm{w})$ powdered $V$. amygdalina leaves mixed with standard grower mash demonstrated the natural skin colour restoration effects of $V$. amygdalina leaf extract. At the end of the 65 days treatment, $V$. amygdalina in the reconstituted rat feed "grossly turned the skin of the treated rats lighter than those of the control rats fed the standard grower mash" (Hafidh et al.,, 2009) Microscopic examinations of the treated rats showed that the various tissues of the rats were of normal architecture with good cellular morphology (Azadi and Farzaneh, 2010).

The $\alpha$-adrenergic receptor on the melanophores of melanocytes has been shown to be associated with the expression and change of skin colour (Harrison and Bartels, 2006). Skin colour in lizards (Anolis carolinensis) and frogs (Rana pipiens) is influenced by both Melanocyte-Stmulating (MSH) hormone and catecholamines. MSH-induced darkening of the skin can be inhibited or reversed by drugs with $\alpha$-adrenorceptor activity (Alipoor et al., 2009). The $\alpha$-adrenorceptor on melanocytes inhibitory to dispersion of granules is the $\alpha_{2}$ subtype (Kim et al., 2006) Clonidine mimicked

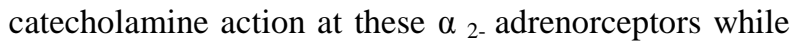
yohimbine antagonized the effect of clonidine and prazocin had negligible effect on them (Haziri et al., 2010).

$V$. amygdalina leaf extract is suggested to have produced its skin lightening and natural skin colour restoration effects in this study through an inhibitory action on the $\alpha_{2}$ receptors of the melanophores of skin melanocytes of the subject.

The body calming effects of $V$. amygdalina reported by the subject and inferred visually in the before and after treatment pictures of the subject are suggested to be due to inhibition of energy metabolism of the subject by the $V$. amygdalina extract.

\section{REFERENCES}

Abu-Al-Basal, M.A., 2009. In vitro and In vivo AntiMicrobial effects of Nigella sativa linn. seed extracts against clinical isolates from skin wound infections. Am. J. Applied Sci., 6: 1440-1447. DOI: 10.3844/ajassp.2009.1440.1447

Al-Akhras, M.A.H., A. Amin, K. Mohammad, F. AlHaddad and A. Hamza, 2007. In vitro studies on the effect of phototoxicity of a new photosensitizer extracted from flowers and aerial parts of Cichorium pumilum. Am. J. Pharmacol. Toxicol., 2: 39-45. DOI: 10.3844/ajptsp.2007.39.45

Alkassasbeh, J.Y.M., L.Y. Heng and S. Surif, 2009. Toxicity testing and the effect of landfill leachate in Malaysia on behavior of common carp (Cyprinus carpio L., 1758; Pisces, Cyprinidae). Am. J. Environ. Sci., 5: 209-217. DOI: 10.3844/ajessp.2009.209.217

Azadi, H.G. and N. Farzaneh, 2010. Comparison of Two Regimens of Nigella sativa Extract for Treatment of Subclinical Mastitis Caused by Staphylococcus aureus. Am. J. Applied Sci., 7: 1210-1214. DOI: 10.3844/ajassp.2010.1210.1214

Hafidh, R.R., A.S. Abdulamir, F.A. Bakar, F. Abas and F. Jahanshiri et al., 2009. Antioxidant Research in Asia in the Period from 2000-2008. Am. J. Pharmacol. Toxicol., 4: 56-74. DOI: 10.3844/ajptsp.2009.56.74

Harrison, A.P. and E.M. Bartels, 2006. A modern appraisal of ancient etruscan herbal practices. Am. J. Pharmacol. Toxicol., 1: 26-29. DOI: 10.3844/ajptsp.2006.26.29

Alipoor, S., A.M. Goodarzi, M.Z. Nezhad and L. Zaheri, 2009. Analysis of the relationship between physical self-concept and body image dissatisfaction in female students. J. Soc. Sci., 5: 60-66. DOI: $10.3844 /$ jssp.2009.60.66 
Haziri, A.I., N. Aliaga, M. Ismaili, S. Govori-Odai and O. Leci et al., 2010. Secondary metabolites in essential oil of Achillea millefolium (L.) growing wild in east part of kosova. Am. J. Biochem. Biotechnol., $\quad 6$ : $32-34 . \quad$ DOI: 10.3844/ajbbsp.2010.32.34

Kim, J.S., J.B. Ju, C.W. Choi and S.C. Kim, 2006. Hypoglycemic and antihyperlipidemic effect of four korean medicinal plants in alloxan induced diabetic rats. Am. J. Biochem. Biotechnol., 2: 154160. DOI: 10.3844/ajbbsp.2006.154.160

Krishna, K.L., K. Mruthunjaya and J.A. Patel, 2009. Antioxidant and hepatoprotective activity of leaf extract of Justicia gendarussa burm. Int. J. Biol. Chemi., 3: 99-110. DOI: 10.3923/ijbc.2009.99.110

Liu, L., H. Zhou, S. Sun, Q. Wang and G. Li, 2005. The effects of chinese traditional processing method on components in semen sinapis albae. Am. J. Biochem. Biotechnol., 1: 64-68. DOI: 10.3844/ajbbsp.2005.64.68
Nayak, S., 2006. Influence of ethanol extract of vinca rosea on wound healing in diabetic rats. OnLine J. Biol. Sci., 6: 51-55. DOI: 10.3844/ojbsci.2006.51.55

Sudha, A., V.S. Murty and T.S. Chandra, 2009. Standardization of metal-based herbal medicines. Am. J. Infect. Dis., 5: 193-199. DOI: 10.3844/ajidsp.2009.193.199

Tong-Un, T., P. Wannanon, J. Wattanathorn and W. Phachonpai, 2010. Quercetin liposomes via nasal administration reduce anxiety and depression-like behaviors and enhance cognitive performances in rats. Am. J. Pharmacol. Toxicol., 5: 80-88. DOI: 10.3844/ajptsp.2010.80.88 